\title{
Revisiting medication use in a frail 93-year-old man experiencing possible adverse effects
}

\author{
Barbara Farrell BScPhm PharmD, Anne Monahan MD, Wade Thompson BScPhm
}

See also the practice article by Farrell and colleagues at www.cmaj.ca/lookup/doi/10.1503/cmaj.122012 (Oct. 1 issue) and the commentary by Frank at www.cmaj.ca/lookup/doi/10.1503/cmaj.131568 (page 407, this issue)

This article is one of several prepared as part of a collaboration between the Geriatric Day Hospital of Bruyère Continuing Care, CMAJ, Canadian Family Physician and the Canadian Pharmacists Journal to assist clinicians in the prevention and management of polypharmacy when caring for older patients in their practices.

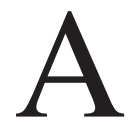
93-year-old man was referred to a geriatric day hospital for assessment of falls, mobility, mood and function. A month earlier, he had presented to a local hospital following a fall that resulted in lacerations to his right arm. At that time, he reported worsening balance and frequent falls over several months, as well as low mood. Comorbidities included coronary artery disease with previous myocardial infarction and angioplasty 15 years earlier, carotid endarterectomy, hypertension, vertebral fractures, bullous pemphigoid and osteoporosis. Most instrumental activities of daily living (e.g., laundry, food preparation) were managed by staff at his retirement home. The patient maintained responsibility for taking his medications from pharmacy-prepared blister packs; his daughter described his compliance as good (see Box 1 for the list of medications).

At presentation, additional problems of low blood pressure, dizziness, daytime sedation, low energy, diarrhea, vitamin deficiencies and hyponatremia were highlighted. The patient accepted a 12-week admission to the geriatric day hospital, and twice-weekly transportation was organized.

At his first few visits, orthostatic hypotension was noted (on 2 occasions, his blood pressure dropped from $115 / 55 \mathrm{~mm} \mathrm{Hg}$ supine to $83 / 42 \mathrm{~mm} \mathrm{Hg}$ standing, and from $127 / 70 \mathrm{~mm} \mathrm{Hg}$ supine to $97 / 64 \mathrm{~mm} \mathrm{Hg}$ standing) and was associated with dizziness when the patient stood up quickly or bent forward. He described sleep as good, although he reported taking 1.5-2 hours to fall asleep and a need to go to the bathroom twice nightly. He had little energy and napped up to 6 hours daily. Low energy and anhedonia meant he had given up several activities, and he had lost weight because of a poor appetite. Despite this, he felt he was not depressed. $\mathrm{He}$ reported bouts of diarrhea every 4-5 days starting in the last 2-3 months and 4-5 episodes of fecal incontinence over this period. Blood work showed vitamin $\mathrm{B}_{12}$ deficiency $(189 \mathrm{pmol} / \mathrm{L}$; sufficient $>220 \mathrm{pmol} / \mathrm{L}$ ), vitamin $\mathrm{D}$ deficiency ( $49 \mathrm{nmol} / \mathrm{L}$; sufficient $>76 \mathrm{nmol} / \mathrm{L}$ ), hyponatremia (sodium $132 \mathrm{mmol} / \mathrm{L}$; normal $135-145 \mathrm{mmol} / \mathrm{L}$ ) and a slightly low calcium level of $2.15 \mathrm{mmol} / \mathrm{L}$ (normal 2.20-2.65 mmol/L). Creatinine clearance was calculated as $30 \mathrm{~mL} / \mathrm{min}$ (Cockroft-Gault equation with adjusted body weight).

An interprofessional care plan was developed to address these issues. The pharmacist at the geriatric day hospital conducted a medication assessment, which included a 45-minute comprehensive interview with the patient and chart review. Each medication was assessed for indication, effectiveness, safety, compliance and patient understanding. ${ }^{1}$ Results of the initial medication assessment are outlined in Appendix 1 (available at www.cmaj.ca/lookup/suppl/doi :10.1503/cmaj.130523/-/DC1). Signs and symptoms were assessed to determine potential drugrelated causes. ${ }^{2}$ The complete medication assessment and care plan are outlined in Box 2 .

\section{KEY POINTS}

- All older people should have their medications reviewed regularly to assess ongoing indications and potential adverse effects and to minimize pill burden.

- A new symptom or problem may be an adverse effect of one or more medications.

- Age-appropriate evidence-based targets can help to determine the need for ongoing treatment.

- Tapering of doses and discontinuation of medications can be considered to determine whether a drug is still required. 
Throughout the admission, several changes were made to the patient's medications (Appendix 2, available at www.cmaj.ca/lookup/suppl/doi :10.1503/cmaj.130523/-/DC1).

The patient participated in balance, strength and mobility exercises with the hospital's physiotherapist, focusing particularly on gait training with and without aids. His Berg Balance score improved from 42 to 54 out of 56 (a 12-point improvement is associated with a clinically sig-

\begin{tabular}{|ll|}
\hline Box 1: Initial list of medications & \\
\hline Medication, dosage & \multicolumn{1}{c|}{ Reason for use, if known } \\
\hline Telmisartan $80 \mathrm{mg} / \mathrm{d}$ & CAD/MI (15 yr earlier) \\
\hline Metoprolol $50 \mathrm{mg} / \mathrm{d}$ & CAD/MI (15 yr earlier) \\
\hline Escitalopram $10 \mathrm{mg} / \mathrm{d}$ & Depression \\
\hline Lorazepam $1 \mathrm{mg}$ at bedtime as needed & Insomnia \\
\hline Tamsulosin CR $0.4 \mathrm{mg}$ at bedtime & Nocturia \\
\hline Pantoprazole $40 \mathrm{mg}$ twice daily & Gastrointestinal bleed (7 mo earlier) \\
\hline Prednisone $5 \mathrm{mg}$ twice daily & Bullous pemphigoid \\
\hline Loperamide $1 \mathrm{mg}$ as needed & Diarrhea \\
\hline Note: CAD = coronary artery disease, CR = controlled release, MI = myocardial infarction. \\
\hline
\end{tabular}

nificant reduction in risk of falls and improvement in function). ${ }^{3,4} \mathrm{His} 6$-minute walk test improved from $240 \mathrm{~m}$ to $390 \mathrm{~m}$ (a $50-\mathrm{m}$ improvement is estimated to be clinically significant for most patients). ${ }^{5}$ His confidence in climbing stairs improved substantially. The patient received fall-prevention education from the occupational therapist one on one and in group classes. No further falls were reported during the 12-week admission period.

The patient's mood improved following supportive counselling from the social worker and increased social interaction. His appetite and energy levels increased, and he resumed old activities. His diarrhea resolved. His blood pressure improved, and he no longer had dizziness; the nurse provided strategies to manage symptoms of orthostatic hypotension should they occur again. A final medication list is presented in Box 3.

\section{Discussion}

As people reach their 80 s and 90 s, regular reviews of their medications are important to assess ongoing indications and potential adverse effects and to minimize pill burden. A new

Box 2: Complete assessment of medications for potential drug-related problems and resulting medication care plan

\begin{tabular}{|c|c|c|}
\hline Potential drug-related problem & Action plan & Monitoring (by team) \\
\hline $\begin{array}{l}\text { Diarrhea and hyponatremia } \\
\text { - May be contributed to by: } \\
\text { - Escitalopram (other than low energy, } \\
\text { patient has no major depressive } \\
\text { symptoms) } \\
\text { - Pantoprazole (likely no longer } \\
\text { needed given gastrointestinal bleed } \\
\text { was } 7 \text { mo earlier) } \\
\text { - Telmisartan }\end{array}$ & $\begin{array}{l}\text { 1. Decrease escitalopram to } 5 \mathrm{mg} / \mathrm{d} \text { for } \\
2-4 \mathrm{wk} \text {, then stop } \\
\text { 2. Stop pantoprazole and start rabeprazole } \\
20 \mathrm{mg} / \mathrm{d} \text { for } 2 \mathrm{wk} \\
\text { 3. Decrease rabeprazole dose to } 10 \mathrm{mg} / \mathrm{d} \text { for } \\
\text { 2-4 wk, then stop } \\
\text { 4. Use calcium carbonate or alginate or low- } \\
\text { dose ranitidine as needed for rebound } \\
\text { heartburn } \\
\text { 5. Decrease telmisartan dose gradually to } \\
40 \mathrm{mg} \text { daily, then to } 20 \mathrm{mg} \text { daily if possible }\end{array}$ & $\begin{array}{l}\text { - Bowel movements, stool } \\
\text { consistency, need for loperamide } \\
\text { - Mood } \\
\text { - Withdrawal effects of SSRI } \\
\text { discontinuation (e.g., sweating, } \\
\text { nausea, insomnia, tremor) } \\
\text { - Rebound heartburn for } 2-4 \mathrm{wk} \\
\text { - Blood pressure target: } \\
120 / 60 \mathrm{~mm} \text { Hg to } 150 / 90 \mathrm{~mm} \mathrm{Hg}\end{array}$ \\
\hline $\begin{array}{l}\text { Orthostatic hypotension and dizziness } \\
\text { - May be contributed to by: } \\
\text { - Metoprolol (no longer required } \\
\text { given Ml was } 15 \text { yr earlier and no } \\
\text { other compelling indications) } \\
\text { - Telmisartan }\end{array}$ & $\begin{array}{l}\text { 1. Decrease metoprolol to } 25 \mathrm{mg} / \mathrm{d} \text { for } 2 \mathrm{wk} \text {, } \\
\text { then to } 12.5 \mathrm{mg} / \mathrm{d} \text { for } 1 \mathrm{wk} \text {, then stop } \\
\text { 2. If blood pressure is still below target } \\
\text { range, reduce telmisartan dose (see } \\
\text { tapering plan above) }\end{array}$ & $\begin{array}{l}\text { - Angina, tachycardia } \\
\text { - Orthostatic hypotension, dizziness } \\
\text { - Blood pressure target: } \\
120 / 60 \mathrm{~mm} \text { Hg to } 150 / 90 \mathrm{~mm} \mathrm{Hg}\end{array}$ \\
\hline $\begin{array}{l}\text { Frequent falls and daytime fatigue and } \\
\text { sleeping } \\
\text { - May be contributed to by lorazepam }\end{array}$ & $\begin{array}{l}\text { Decrease lorazepam to } 0.5 \mathrm{mg} \text { at bedtime } \\
\text { for } 2 \mathrm{wk} \text {, then to } 0.25 \mathrm{mg} \text { at bedtime for } \\
2 \mathrm{wk} \text {, then stop }\end{array}$ & $\begin{array}{l}\text { - Sleep } \\
\text { - Anxiety, tremor }\end{array}$ \\
\hline $\begin{array}{l}\text { Vitamin D deficiency }(49 \mathrm{nmol} / \mathrm{L}) \text { and } \\
\text { increased risk of falls }\end{array}$ & Start vitamin D $1000 \mathrm{IU} / \mathrm{d}$ & \\
\hline Vitamin $B_{12}$ deficiency (189 pmol/L) & Start vitamin $B_{12} 1000 \mu \mathrm{g} / \mathrm{d}$ & \\
\hline Risk of adverse effects with prednisone & $\begin{array}{l}\text { Consider slowly tapering prednisone dose } \\
\text { (e.g., from } 5 \mathrm{mg} \text { twice daily to } 7.5 \mathrm{mg} \text { once } \\
\text { daily for } 1 \mathrm{mo} \text {, then to } 5 \mathrm{mg} \text { once daily for } \\
1 \mathrm{mo} \text {, and so on) }\end{array}$ & \\
\hline
\end{tabular}




\section{In the morning \\ - Telmisartan $20 \mathrm{mg}$ \\ - Prednisone $5 \mathrm{mg}$ \\ - Vitamin D $1000 \mathrm{IU}$ \\ - Vitamin $B_{12} 1000 \mu \mathrm{g}$ \\ - Psyllium $15 \mathrm{~mL}$ \\ At supper \\ - Prednisone $5 \mathrm{mg}$ \\ At bedtime \\ - Tamsulosin CR $0.4 \mathrm{mg}$ \\ $\mathrm{CR}=$ controlled release}

Box 3: Medication schedule at discharge

symptom or problem may be an adverse effect of one or more medications. ${ }^{6}$ Recognizing and addressing the contribution of a drug to a symptom may prevent prescribing cascades, whereby new drugs are given to treat an adverse effect instead of stopping the drug causing the effect. Reviewing the indications and evidence for continuing long-standing drugs, and weighing the benefits against the risk of adverse events, can reduce the number of medications a patient is taking. Figure 1 illustrates the interplay among the patient's medications and the possible effects on his diarrhea, dizziness and risk of falls.

\section{Diarrhea and hyponatremia}

Diarrhea is a common problem for older people and can have a strong negative impact on their quality of life and function. ${ }^{7}$ Antibiotics, selective serotonin reuptake inhibitors (SSRIs), proton pump inhibitors and angiotensin-receptor blockers have all been shown to increase the risk of diarrhea in older patients. ${ }^{7}$ Hyponatremia has also been associated with several SSRIs, a problem that occurs predominantly in older people. ${ }^{8}$

The onset of our patient's diarrhea was consistent with the initiation of escitalopram for the treatment of depression about 2-3 months before his admission to the geriatric day hospital. Hyponatremia may have been caused or worsened by the escitalopram use, or exacerbated by the diarrhea. In light of these safety concerns, the drug was tapered and eventually stopped, during which the patient was monitored for mood changes and signs of adverse withdrawal events, in this case SSRI discontinuation syndrome (e.g., anxiety, insomnia, irritability, headache, dizziness and fatigue).

High-dose pantoprazole treatment was being taken following a gastrointestinal bleed secondary to naproxen use 7 months before presentation. Treatment with a proton pump inhibitor for this indication usually does not exceed 8 weeks and need not be lifelong if the offending nonsteroidal anti-inflammatory drug (NSAID) is stopped. ${ }^{9}$
Naproxen had been stopped following the gastrointestinal bleed, and the patient had no ongoing reflux or symptoms of a peptic ulcer. Evidence shows that corticosteroids do not increase the risk of peptic ulceration unless NSAIDs are being taken concomitantly. ${ }^{10}$ Thus, pantoprazole was considered to be no longer necessary and was switched to low-dose rabeprazole (the only lowdose proton pump inhibitor covered by the provincial formulary without a special code), which was then tapered and eventually stopped. Two minor instances of expected rebound heartburn ${ }^{11}$ were managed with calcium carbonate.

Telmisartan may have also been contributing to the patient's diarrhea. Given the hypotension that was observed (discussed in the next section), the dose was reduced.

Following these medication changes, the patient's bowel symptoms improved to the point where he no longer reported diarrhea or episodes of fecal incontinence and loperamide was no longer needed. Psyllium was started to provide bulk for occasional loose stools. The patient reported normal bowel movements by the time of discharge. His mood was stable during the tapering of the escitalopram and improved during his visits to the geriatric day hospital, even after stopping the escitalopram.

\section{Hypotension, dizziness and falls}

Both metoprolol and telmisartan may have been contributing to the patient's hypotension, dizziness and falls. The hypotension may have been a major factor contributing to his falls, but it also

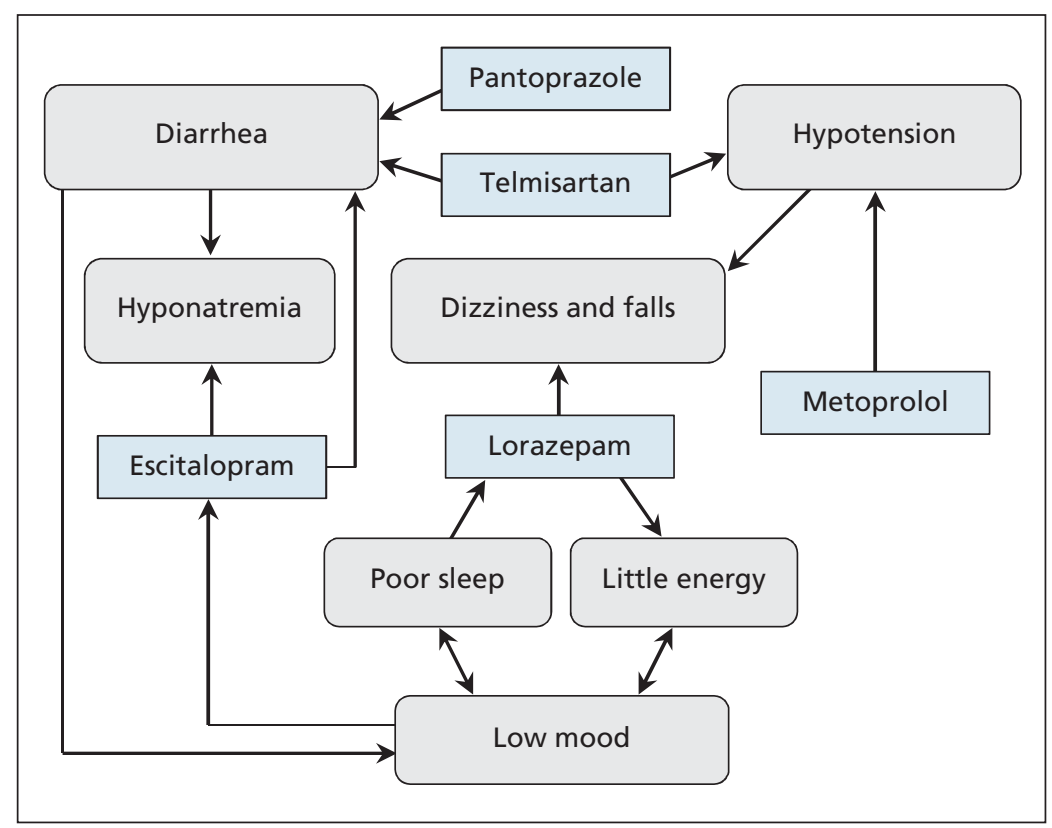

Figure 1: Interplay among the medications of a 93-year-old man referred to a geriatric day hospital and their possible effects on his diarrhea, dizziness and risk of falls. 
was of concern because low systolic pressure is associated with increased cardiovascular mortality among patients over $85 .{ }^{12}$ A target range of $120 / 60 \mathrm{~mm} \mathrm{Hg}$ to $150 / 90 \mathrm{~mm} \mathrm{Hg}$ was established to guide treatment.

Because the patient's myocardial infarction had occurred 15 years earlier, without subsequent angina or other compelling indications for $\beta$ blocker therapy, such as heart failure or atrial fibrillation, the benefit of continuing the metoprolol treatment was questioned. The optimal duration of $\beta$-blocker therapy following myocardial infarction is not well established, because there is limited evidence to guide recommendations beyond 2 years of treatment. A large meta-analysis investigating $\beta$-blocker use for an average of 1.4 years after myocardial infarction reported a significant reduction in mortality over this time (number needed to treat for $2 \mathrm{yr}$ to prevent 1 death was 42). ${ }^{13}$ A more recent observational study followed a cohort of patients for an average of 44 months after myocardial infarction. Beyond 2 years of follow-up, no significant difference in cardiovascular-related death, nonfatal myocardial infarction or nonfatal stroke was seen among patients taking a $\beta$-blocker compared with those not taking one. ${ }^{14}$

Because of safety concerns regarding hypotension (with attendant cardiovascular risks), dizziness and falls, we decided to taper and stop the metoprolol. Following its discontinuation, we monitored the patient's blood pressure and heart rate and watched for any rebound angina and common adverse withdrawal events associated with $\beta$-blockers (e.g., tachycardia). ${ }^{15}$ The patient did not experience rebound angina or tachycardia; however, his blood pressure was still below target, so we gradually decreased the dose of telmisartan from 80 to 20 $\mathrm{mg} / \mathrm{d}$, also taking into account the drug's possible contribution to diarrhea. The patient's blood pressure subsequently rose to within target range (e.g., $132 / 70 \mathrm{~mm} \mathrm{Hg}$ ) by discharge.

Because of the increased risk of injurious falls with benzodiazepine use among communitydwelling people over 80 years old, ${ }^{16}$ we identified lorazepam as a possible contributor to the patient's falls and dizziness as well as his daytime sedation. He had started taking lorazepam $1 \mathrm{mg}$ at bedtime several months before coming to the geriatric day hospital and noted worsening balance and more falls over this time. We slowly tapered ${ }^{17}$ and stopped the lorazepam over 7 weeks, with no worsening of his sleep, no rebound insomnia or adverse withdrawal events reported.

Vitamin D supplementation was started, given the patient's deficiency and the potential for vitamin D to reduce the risk of falls. ${ }^{18}$

With our interprofessional approach to falls prevention and these medication changes, the patient's dizziness resolved and no further falls were reported.

\section{Osteoporosis}

Long-term adverse effects of corticosteroids are well-documented and include osteoporosis and diabetes. ${ }^{19}$ It was not clear whether the patient still needed daily prednisone treatment to manage his bullous pemphigoid. However, following a trial decrease in the dose from $5 \mathrm{mg}$ twice daily to $7.5 \mathrm{mg}$ once daily, the patient reported a worsening of his symptoms and marked itchiness of his back; the original dosage was reinstated. Treatment with a bisphosphonate was considered owing to the long-term corticosteroid use; however, it was not started because of the patient's low renal function and advanced age; this decision was deferred for discussion with his family physician. Although vitamin D supplementation was started, calcium supplementation was not required because his dietary calcium intake was about 1000 mg/d.

\section{Conclusion}

This patient's case underscores the importance of assessing drug-related causes of symptoms in older patients and whether the causative agent is still required. Few drug trials include participants in their 80 s or 90 s, and given pharmacokinetic and pharmacodynamic changes in older people, little is known about the safety and effectiveness of medications in this patient group. Slow tapering with careful monitoring can help to identify medications that are causing adverse effects as well as medications that are still needed for symptom relief.

A pharmacist and physician, working together with support and interventions from other members of an interprofessional team, can make an important difference in the quality of life of older patients by reassessing their medications to ensure they are safe and effective. In the case of our patient, his low energy, diarrhea, dizziness and falls were severely affecting his quality of life. Three months later, he had more energy, improved appetite, normal bowel function, improved balance and mobility, no dizziness and no further falls.

\section{References}

1. Cipolle RD, Strand LM, Morley PC, editors. Pharmaceutical care practice: the clinician's guide. 2nd ed. New York (NY): McGraw-Hill; 2004

2. Winslade N, Bajcar J. Therapeutic thought process algorithm. Ottawa $(\mathrm{ON})$ : National Association of Pharmacy Regulatory Authorities; 1995. Available: www.napra.org/Content_Files /Files/algorithm.pdf (accessed 2012 Dec. 3).

3. Shumway-Cook A, Baldwin M, Polissar N, et al. Predicting the probability of falls in community-dwelling older adults. Phys Ther 1997;77:812-9.

4. Conradsson M, Lundin-Olsson L, Lindelof N, et al. Berg balance scale: intra-rater test-retest reliability among older people dependent in activities of daily living and living in residential care facilities. Phys Ther 2007;87:1155-63. 
5. Perera S, Mody S, Woodman R, et al. Meaningful change and responsiveness in common physical performance measures in older adults. J Am Geriatr Soc 2006;54:743-9.

6. Salazar JA, Poon I, Nair M. Clinical consequences of polypharmacy in elderly: expect the unexpected, think the unthinkable. Expert Opin Drug Saf 2007:6:695-704.

7. Pilotto A, Franceschi M, Vitale D, et al. The prevalence of diarrhea and its association with drug use in elderly outpatients: a multicenter study. Am J Gastroenterol 2008;103:2816-23.

8. Jacob S, Spinler SA. Hyponatremia associated with selective serotonin-reuptake inhibitors in older adults. Ann Pharmacother 2006;40:1618-22.

9. Ramakrishnan K, Salinas RC. Peptic ulcer disease. Am Fam Physician 2007;76:1005-12.

10. Conn HO, Poynard T. Corticosteroids and peptic ulcer: metaanalysis of adverse events during steroid therapy. J Intern Med 1994;236:619-32.

11. Reimer C, Søndergaard B, Hilsted L, et al. Proton-pump inhibitor therapy induces acid-related symptoms in healthy volunteers after withdrawal of therapy. Gastroenterology 2009;137:80-7

12. Molander L, Lovheim H, Norman T, et al. Lower systolic blood pressure is associated with greater mortality in people aged 85 and older. J Am Geriatr Soc 2008;56:1853-9.

13. Freemantle N, Cleland J, Young P, et al. Beta blockade after myocardial infarction: systematic review and meta regression analysis. BMJ 1999;318:1730-7.

14. Bangalore S, Steg G, Deedwania P, et al. Beta blocker use and clinical outcomes in stable outpatients with and without coronary artery disease. JAMA 2012;308:1340-9.

15. Graves T, Hanlon JT, Schmader KE, et al. Adverse events after discontinuing medications in elderly outpatients. Arch Intern Med 1997;157:2205-10.

16. Pariente A, Dartigues JF, Benichou J, et al. Benzodiazepines and injurious falls in community dwelling elders. Drugs Aging 2008; 25:61-70.

17. Chen C, Farrell B, Ward N, et al. Stopping benzodiazepines: an interdisciplinary approach at a geriatric day hospital. Can Pharm J 2010;143:286-95.

18. Bischoff-Ferrari HA, Dawson-Hughes B, Staehelin HB, et al Fall prevention with supplemental and active forms of vitamin D: a meta-analysis of randomised controlled trials. BMJ 2009; 339:b3692.

19. Stanbury RM, Graham EM. Systemic corticosteroid therapy — side effects and their management. Br J Ophthalmol 1998;82:704-8.
Affiliations: Geriatric Day Hospital of Bruyère Continuing Care (Farrell, Monahan, Thompson), Ottawa, Ont.; C.T. Lamont Primary Health Care Research Centre (Farrell), Bruyère Research Institute, Ottawa, Ont.; Department of Family Medicine (Farrell, Monahan), University of Ottawa, Ottawa, Ont.; School of Pharmacy (Thompson), University of Waterloo, Waterloo, Ont.

Contributors: Barbara Farrell and Anne Monahan were the clinicians involved in the care of the patient. Wade Thompson prepared the initial draft of the manuscript and conducted relevant literature searches. All of the authors revised the manuscript critically for important intellectual content and approved the final version submitted for publication.

\section{Resources for clinicians}

- Tisdale JE, Miller DA, editors. Drug-induced diseases: prevention, detection and management. 2nd ed. Bethesda (MD): American Society of Health System Pharmacists; 2010.

- Alexander GC, Sayla MA, Holmes HM, et al. Prioritizing and stopping prescription medications. CMAJ 2006;174:1083-4.

- A practical guide to stopping medicines in older people. Best Pract J 2010;27:10-23.

- Hajjar ER, Gray SL, Guay DR, et al. Geriatrics. In: Talbert RL, DiPiro JT, Matzke GR, editors. Pharmacotherapy: a pathophysiologic approach. 8th ed. New York (NY): McGraw-Hill; 2011. Available: http://accesspharmacy .com/content.aspx?aid=7967419

- Kwan D, Farrell B. Polypharmacy - optimizing medication use in elderly patients. Pharmacy Practice 2012;29:20-5.

An expanded version of this article is available as a tool to teach about interprofessional approaches to the management of polypharmacy (see Appendix 3, available at www.cmaj.ca/lookup/suppl/doi:10.1503/cmaj.130523/-/DC1).

\title{
How you can get involved in the CMA!
}

The CMA is committed to providing leadership for physicians and promoting the highest standard of health and health care for Canadians. To strengthen the association and be truly representative of all Canadian physicians the CMA needs to hear from members interested in serving in elected positions and on appointed committees and advisory groups. The CMA structure comprises both governing bodies and advisory bodies either elected by General Council or appointed by the CMA Board of Directors. The Board of Directors - elected by General Council - has provincial/territorial, resident and student representation, is responsible for the overall operation of the CMA and reports to General Council on issues of governance.

CMA committees advise the Board of Directors and make recommendations on specific issues of concern to physicians and the public. Five core committees mainly consist of regional, resident and student representation while other statutory and special committees and task forces consist of individuals with interest and expertise in subject-specific fields. Positions on one or more of these committees may become available in the coming year.

For further information on how you can get involved please go to http://www.cma.ca/membercentre/how-you-can-get-involved, or contact

\author{
Cherise Araujo \\ Corporate and Governance Services \\ Canadian Medical Association \\ 1867 Alta Vista Drive, Ottawa ON K1G 5 W8 \\ Fax 613 526-7570, Tel 800 663-7336 x1949 \\ cherise.araujo@cma.ca
}

By getting involved, you will have an opportunity to make a difference.

We hope to hear from you!

ASSOCIATION
MÉDICALE
CANADIENNE

